\title{
Development of Probiotics for Helicobacter pylori Infection
}

\author{
Katsunori Kımura, ${ }^{1 *}$ Ichiko SaKamoto, ${ }^{2,3}$ Muneki Igarashl, ${ }^{3}$ Atsushi Takagl, ${ }^{3}$ Takeshi Miwa, ${ }^{3}$ \\ Yuji AlBa ${ }^{2}$ and Yasuhiro Koga ${ }^{2}$ \\ 1 Food Functionality Research Institute, Meiii Dairies Corporation, 540 Naruda, Odawara, Kanagawa 250-0862, Japan \\ 2 Department of Infectious Diseases, ${ }^{3}$ Department of Internal Medicine, Tokai University School of Medicine, Isehara, Kanagawa \\ 259-1193, Japan \\ Received for publication, July 8, 2002
}

To develop probiotics for Helicobacter pylori infection, we screened 203 Latobacillus strains. Lactobacillus gasseri OLL2716 (LG21) was selected as the most effective strain to inhibit the growth of $H$. pylori by in vitro tests and animal study. We examined the effects of yogurt containing LG21 on $\mathrm{H}$. pylori infection in humans. The intake of yogurt containing LG21 both decreases the number of $H$.pylori and also reduces mucosal inflammation. LG21 was shown to be effective as a probiotic for $H$. pylori infection.

Key words: Lactobacillus gasseri; Helicobacter pylori; probiotics; LG21; mucosal inflammation

\section{INTRODUCTION}

The evidence of a relationship between Helicobacter pylori and gastric diseases has gradually become clear since Warren and Marshall succeeded in cultivating this bacterium in 1982. Since the infection rate of $H$. pylori is very high, about $50 \%$ in Japanese, it is difficult to eradicate $H$. pylori in all people infected. The eradication therapy using antibiotics is often accompanied by side effects and not always successful because of antibiotic-resistant strains.

We found that orally administered lactobacilli could eradicate $H$. pylori in a gnotobiotic murine model ( 1 , 6). So we screened 203 Latobacillus strains to select a strain that exhibited excellent anti- $H$. pylori activity in vitro and in animal studies, and selected Lactobacillus gasseri OLL2716 (LG21) as the most suitable strain for use as a probiotic for $H$. pylori infection.

We also examined the efficacy of LG21 against $H$. pylori infection in humans.

\section{HELICOBACTER PYLORI}

H. pylori is a spiral Gram-negative rod with unipolar flagella. This bacterium inhabits the human stomach and can cause chronic inflammation and ulcers of the stomach and duodenum. $H$. pylori has also been identified as a risk factor for stomach cancer. $H$. pylori has strong urease and can catalyze urea in the stomach to ammonia and carbon dioxide. H. pylori can survive

*Corresponding author. Mailing address: Lactic Acid Bacterial Research Institute, Food Functionality Research Institute, Meiji Dairies Corporation, 540, Naruda, Odawara, Kanagawa 250-0862, Japan. Phone: +81-465-373666. Fax: +81-465-36-2776. E-mail: KATSUNORI_KIMURA @MEIJIMILK.COM under strong acidic conditions because of this ammonia production.

Selection of anti-H. pylori lactic acid bacteria in vitro

To select an anti- $H$. pylori lactic acid bacteria, antiH. pylori abilities (resistance to artificial gastric juice, proliferation under acidic conditions, adherence to cultured gastric epithelial cells, suppression of $H$. pylori during co-fermentation and survival in yogurt) of 203 Lactobacillus strains were examined in vitro. Lactobacillus gasseri OLL2716 (LG21), Lactobacillus gasseri No. 6 and Lactobacillus salivarius WB 1004 were selected as lactic acid bacteria with excellent anti-H. $p y$ lori properties (data not shown).

\section{ANIMAL STUDY}

Following in vitro experiments, the effects of the administration of Lactobacillus strains (LG21, L. gasseri No. 6, L. salivarius WB1004) on H. pylori-infected mice were examined. For $H$. pylori infection, $10^{9} \mathrm{cfu}$ of $H$. pylori were orally administered to germfree mice once a day for 3 days. Six weeks after the administration of $\mathrm{H}$. pylori, $10^{9} \mathrm{cfu}$ of Lactobacillus strains were administered once a week for 8 weeks. One week after finishing the administration of Lactobacillus strains, the number of $H$. pylori and serum anti- $H$. pylori IgG levels were measured.

No $H$. pylori was detected in the mice administered LG21 and L. salivarius WB1004, and the anti-H. pylori IgG levels of the mice administered LG21 were the lowest (Fig. 1). So LG21 was selected as the most suitable strain for use as a probiotic for $H$. pylori infection. 

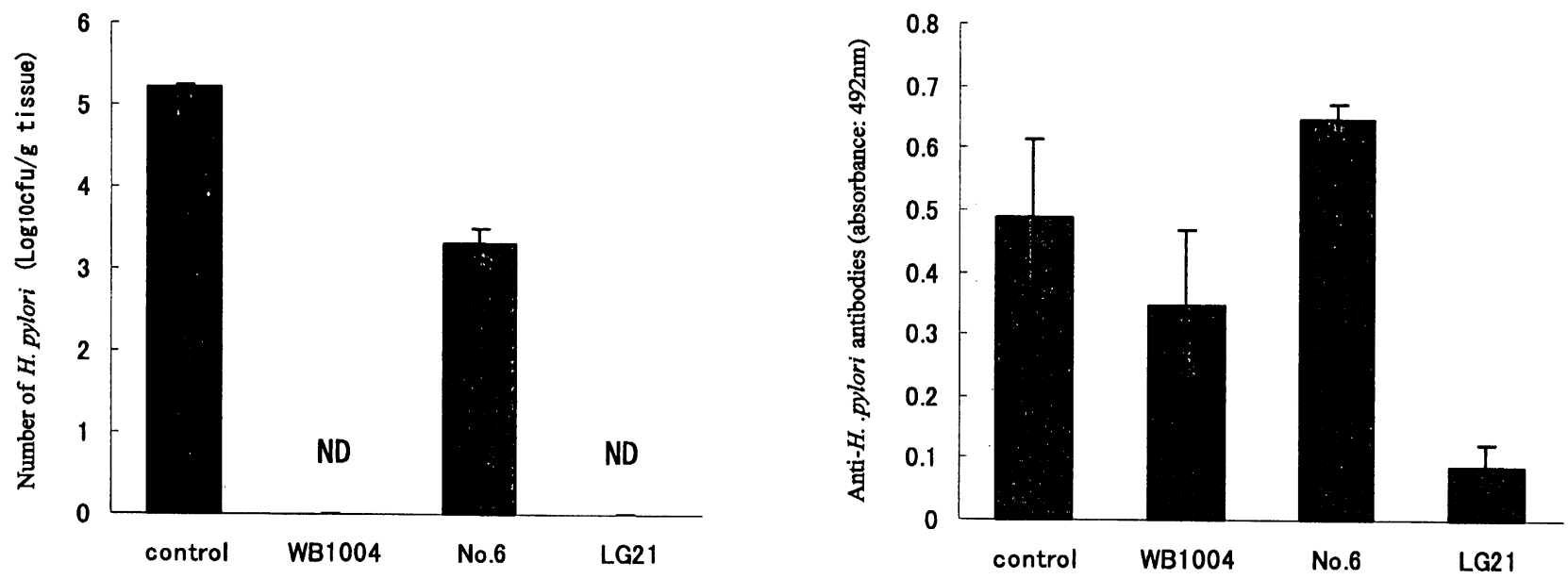

Fig. 1. Effect of LG21 on the number of $H$. pylori and anti- $H$. pylori antibodies of $H$. pylori-infected mice $(8$ weeks, $n=5)$.

\section{EFFECTS OF LG21 ADMINISTRATION ON H. PYLORI INFECTION IN HUMANS}

To examine the efficacy of LG21 against $H$. pylori infection in humans, we performed human clinical studies (12). Thirty-one healthy volunteers infected with H. pylori ingested $90 \mathrm{~g}$ of yogurt twice a day for 8 weeks. From 1 week after the finish of this 8-week intake of yogurt, the volunteers ingested $90 \mathrm{~g}$ of yogurt containing $10^{9} \mathrm{cfu}$ of LG21 twice a day for 8 weeks. The urea breath test and assays of serum pepsinogen $\mathrm{V} /$ II ratios were performed to measure the population of $H$. pylori and to evaluate the degree of mucosal inflammation in the stomach respectively, prior to intake of yogurt, 1 week after finishing the intake of yogurt and 1 week after finishing the intake of yogurt containing LG21. Moreover gastric biopsy specimens of 6 volunteers were taken for quantitative culture both before and after the intake of yogurt containing LG21.

It is known that the urea breath test provides semiquantitative assessments of the density of $H$. pylori colonization of gastric mucosa $(4,10,11)$, and that the serum pepsinogen $\mathrm{I} / \mathrm{II}$ ratio is reduced in $H$. pylori-positive gastritis and gastric ulcer patients $(2,9,13)$ and is correlated with the activity of gastritis (7). A high $\Delta^{13} \mathrm{C}$ value indicates a large population of $H$. pylori and a low pepsinogen I/II ratio indicates severe mucosal inflammation in the stomach.

The $\Delta^{13} \mathrm{C}$ value in the urea breath test did not significantly change after the intake of yogurt, but did significantly decrease following the intake of yogurt containing LG21 (Fig. 2). The pepsinogen I/II ratio did not significantly change after the intake of yogurt, but did significantly increase following the intake of yogurt containing LG21 (Fig. 3). The number of $H$. pylori in the

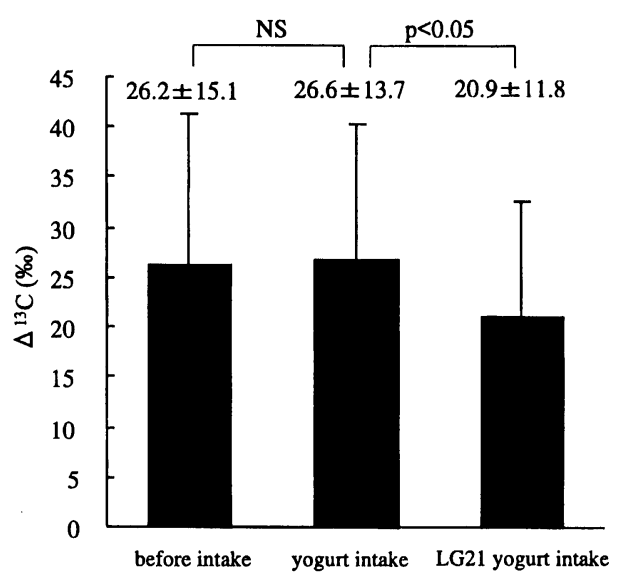

Fig. 2. Effect of yogurt containing LG21 on $\Delta^{13} \mathrm{C}$ value of subjects infected with $H$. pylori.

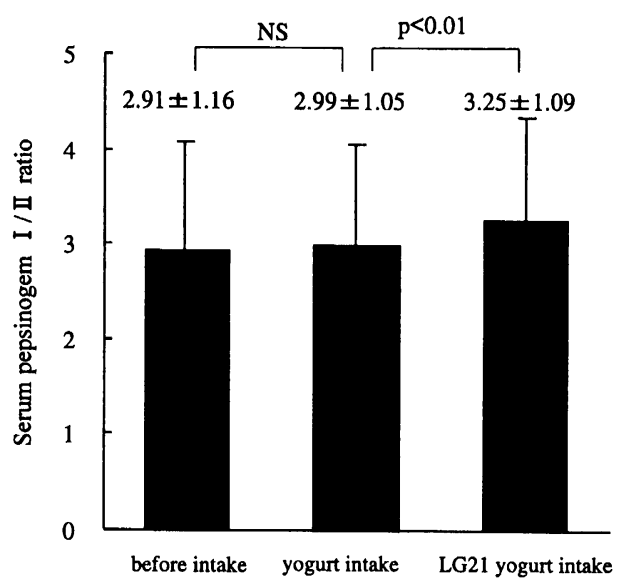

Fig. 3. Effect of yogurt containing LG21 on serum pepsinogen I/II ratio of subjects infected with $H$. pylori. 


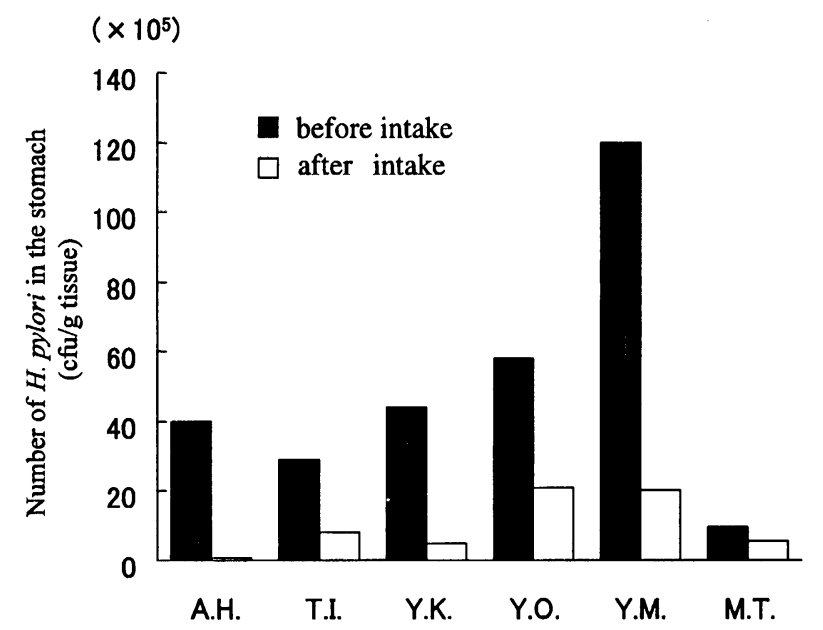

Fig. 4. Change in number of $H$. pylori after consumption of yogurt containing LG21.

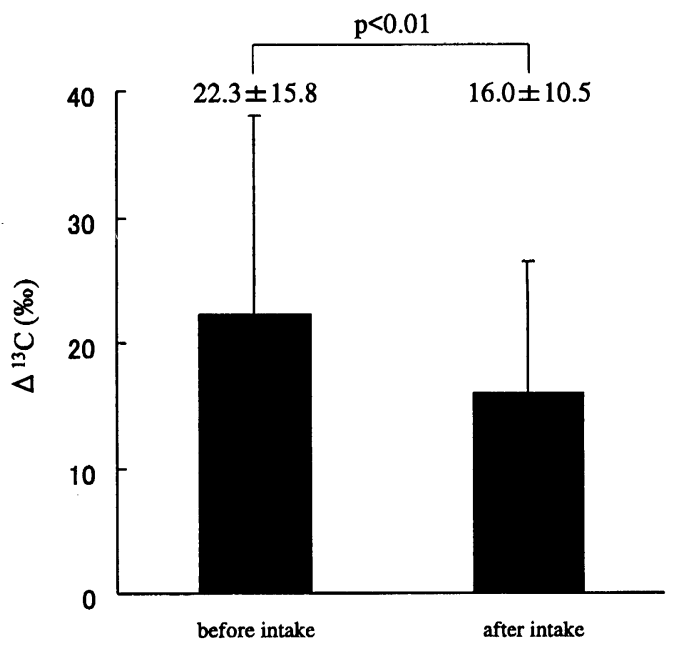

Fig. 5. Effect of yogurt containing LG21 on $\Delta^{13} \mathrm{C}$ value of subjects infected with $H$. pylori.

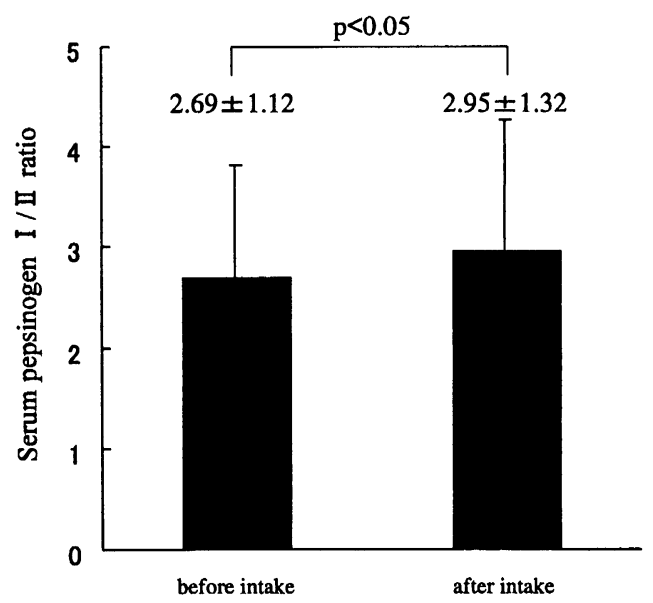

Fig. 6. Effect of yogurt containing LG21 on serum pepsinogen I/II ratio of subjects infected with $H$. pylori. gastric biopsy specimens from all 6 volunteers decreased after the intake of yogurt containing LG21 (Fig. 4).

Next, we examined the effects of long-term administration of yogurt containing LG21 (8). Thirty-one healthy volunteers infected with $H$. pylori ingested 120 $\mathrm{g}$ of yogurt containing $10^{9} \mathrm{cfu}$ of LG21 once a day for 24 weeks. The urea breath test and assays of the serum pepsinogen I/II ratios were performed both before and 1 week after finishing 24-week period of intaking yogurt containing LG21. The $\Delta^{13} \mathrm{C}$ value significantly decreased and the serum pepsinogen I/II ratio significantly increased following the intake of yogurt containing LG21 (Figs. 5, 6). No volunteers complained about adverse effects during the test period.

These results suggest that the intake of yogurt containing LG21 both decreases the number of $H$. pylori and also reduces the mucosal inflammation in the stomach of humans infected with $H$. pylori.

\section{CONCLUSIONS}

LG21 displays inhibitory activity against $H$. pylori both in vitro and in animal studies. In clinical studies, the intake of yogurt containing LG21 decreases the number of $H$. pylori and improves the degree of mucosal inflammation in the stomach of humans infected with $H$. pylori. The density of $H$. pylori colonization in the stomach is of importance in the pathogenesis of infection associated with this bacterium. It was reported that there was a correlation between $H$. pylori density and gastric inflammation and duodenal ulceration (5), and no duodenal ulceration was present in subjects with antral $H$. pylori densities of less than $10^{5} \mathrm{cfu} / \mathrm{g}$ tissue protein (3). Since the intake of yogurt containing LG21 suppresses $H$. pylori in addition to improving inflammation in the stomach, LG21 may reduce the risk of $H$. pylori-induced gastrointestinal diseases.

\section{REFERENCES}

(1) Aiba Y, Suzuki N, Kabir AMA, Takagi A, Koga Y. 1998. Lactic acid-mediated suppression of Helicobacter pylori by the oral administration of Lactobacillus salivarius as a probiotic in a gnotobiotic murine model. Am J Gastroenterol 93: 2097-2101.

(2) Asaka M, Kato M, Kudo M, Meguro T, Kimura T, Miyazaki T, Inoue K. 1992. Relationship of Helicobacter pylori to serum pepsinogens in a asymptomatic Japanese population. Gastroenterol 102: 760-766.

(3) Atherton JC, Tham KT, Peek RM, Cover TL, Blaser MJ. 1996. Density of Helicobacter pylori infection in vivo as assessed by quantitative culture and histology. J Infect Dis 174: 552-556. 
(4) Debongnie JC, Pauwels S, Raat A, de Meeus Y, Haot J, Mainguet P. 1991. Quantification of Helicobacter pylori infection in gastritis and ulcer disease using a simple and rapid carbon-14-urea breath test. J Nucl Med 32: 11921198.

(5) Furuta T, Kaneko E, Baba S, Arai H, Futami H. 1997. Percentage changes in serum pepsinogens are useful as indices of eradication of Helicobacter pylori. Am J Gastroenterol 92: 84-88.

(6) Kabir AMA, Aiba Y, Takagi A, Kamiya S, Miwa T, Koga Y. 1997. Prevention of Helicobacter pylori infection by lactobacilli in a gnotobiotic murine model. Gut 41: 49-55.

(7) Khulusi S, Mendall MA, Patel P, Levy J, Badve S, Northfield TC. 1995. Helicobacter pylori infection density and gastric inflammation in duodenal ulcer and non-ulcer subjects. Gut 37: 319-324.

(8) Kimura K, Sakamoto I, Igarashi M, Takagi A, Miwa T, Koga Y. 2001. Effects of yogurt containing Lactobacillus gasseri OLL2716 (LG21) on decrease of Helicobacter pylori and the improvement of mucosal inflammation in the stomach of humans infected with $H$. pylori. J Nutr Food 4: 29-34 (in Japanese with English summary).

(9) Mossi S, Meyer-Wyss B, Renner EL, Merki HS, Gamboni G, Beglinger C. 1993. Influence of Helicobacter pylori, sex, and age on serum gastrin and pepsinogen concentrations in subjects without symptoms and patients with duodenal ulcer. Gut 34: 752-756.

(10) Perez-Paramo M, Albillos A, Calleja JL, Salas C, Marin MDC, Marcos ML, Cacho G, Escartin P, Ortiz-Berrocal J. 1997. Changes in gastrin and serum pepsinogens in monitoring of Helicobacter pylori response to therapy. Dig Dis Sci 42: 1734-1740.

(11) Perri F, Clemente R, Pastore M, Quitadamo M, Festa V, Bisceglia M, Libergoli M, Lauriola G, Leandro G, Ghoos Y, Rutgeerts P, Andriulli A. 1998 . The ${ }^{13} \mathrm{C}$-urea breath test as a predictor of intragastric bacterial load and severity of Helicobacter pylori gastritis. Scand J Clin Lab Invest 58: 19-28.

(12) Sakamoto I, Igarashi M, Kimura K, Takagi A, Miwa T, Koga Y. 2001. Suppressive effect of Lactobacillus gasseri OLL2716 (LG21) on Helicobacter pylori infection in humans. J Antimicrob Chemother 47: 709-710.

(13) Wagner S, Haruma K, Gladziwa U, Soudah B, Gebel M, Bleck J, Schmidt H, Manns M. 1994. Helicobacter pylori infection and serum pepsinogen $\mathrm{A}$, pepsinogen $\mathrm{C}$, and gastrin in gastritis and peptic ulcer: significance of inflammation and effect of bacterial eradication. Am J Gastroenterol 89: $1211-1218$. 